\title{
When management meets science: adaptive analysis for the optimization of the eradication of the Northern raccoon (Procyon lotor)
}

\author{
Maria Vittoria Mazzamuto ${ }^{(1)}$ - M. Panzeri • F. Bisi • L. A. Wauters • \\ D. Preatoni · A. Martinoli
}

Received: 15 October 2019/Accepted: 9 July 2020/Published online: 21 July 2020

(C) The Author(s) 2020

\begin{abstract}
The EU Regulation no.1143/2014 on invasive species requires the EU Member States to respond promptly and efficiently in eradicating the invasive alien species listed as species of Union concern. The Northern raccoon (Procyon lotor) was introduced in Northern Italy along the river Adda and we carried out its eradication campaign between 2016 and 2019. We used an integrated approach of camera traps and live traps. A standardized approach to the camera trap survey (2904 camera trap-nights) revealed that the detectability of raccoons $(0.27 \pm 0.07 \mathrm{SD})$ increased in the proximity of the river and their occupancy $(0.15 \pm 0.09 \mathrm{SD})$ was higher in urban areas. These results allowed us to increase the trapping success whilst reducing the effort. During the captures, systematic collection of catch and effort data allowed to estimate population size ( $65 \pm 7.8$ raccoons $)$ and thus to have a continuous update on how far the
\end{abstract}

Maria Vittoria Mazzamuto and M. Panzeri contributed equally to this paper

Electronic supplementary material The online version of this article (https://doi.org/10.1007/s10530-020-02313-6) contains supplementary material, which is available to authorized users.

M. V. Mazzamuto $(\bowtie) \cdot$ M. Panzeri · F. Bisi ·

L. A. Wauters - D. Preatoni - A. Martinoli

Environment Analysis and Management Unit - Guido

Tosi Research Group, Dipartimento di Scienze Teoriche e

Applicate, University of Insubria, Varese, Italy

e-mail: maria.mazzamuto@uninsubria.it campaign was from the complete eradication of the species, allowing to adjust the trapping effort accordingly. We captured 69 raccoons (7279 cage trap nights) thanks to both systematic trapping and opportunistic activation of traps following stakeholders' reports. Stakeholders supported the campaign and some of them played an important role in reporting sightings, signs, and allowing access to their private land. Camera trap data also allowed us to make a Rapid Eradication Assessment that estimated an eradication probability of $99 \%$ after 6 months without detections. We finally give indications for future control campaigns on the species to increase removal success, reducing the effort.

Keywords Adda Nord Regional Park · Camera trap · Invasive species · Occupancy · Trapping · Urban

\section{Introduction}

Invasive alien species (IAS) are one of the greatest threats to biodiversity, ecosystem functioning and human wellbeing (Mack et al. 2000; Clavero and García-Berthou 2005; Strayer 2012). The economic cost of biological invasions has dramatically grown in recent decades (e.g. Pimentel 2011; European Environment Agency 2013). In Europe the cost of IAS management and associated damage is estimated to be between EUR 12.5 billion and EUR 20 billion per year 
(Kettunen et al. 2009; Scalera 2010). This threat to the European biodiversity, human health and economy led to the EU Regulation no.1143/2014 that, entering into force in 2015, provides measures to be taken across the EU in relation to IAS (Carboneras et al. 2018). The Regulation aims to reduce the overall risks associated with the spread of IAS thanks to a combination of applied prevention measures, early warning systems, a prompt and efficient response to eradicate the species, or a long-term mitigation and control mechanisms for those species already established (European Environment Agency 2013; Tollington et al. 2017). The EU Member States are required to apply these measures to a provided list of IAS of Union concern (the Union list).

The Northern raccoon (Procyon lotor) is a species included in the Union list because of its invasiveness and the threat it represents to native species and human activities and health. The raccoon is an opportunistic mesocarnivore native to North and Central America that, despite its preference for riparian forests (Heske and Ahlers 2016; Duscher et al. 2018; Fiderer et al. 2019), can adapt to new environments exploiting a wide variety of habitat and food resources (Prange et al. 2004). Raccoons are omnivorous and eat a wide range of plants (seeds, nuts, fruits) and animals like insects, small mammals, amphibians, crabs, fish and birds or bird eggs (Zeveloff 2002; Bartoszewicz et al. 2008; García et al. 2012). They can also eat garbage in urban and suburban areas, where they have become one of the most chronic nuisance animals in North America (Zeveloff 2002; Prange et al. 2003). In Europe the raccoon was first introduced for fur farming, hunting and as pets/attraction in animal parks in Germany in 1934 and in fifty years it spread over the borders colonizing the neighboring countries (Hohmann and Bartussek 2002; Salgado 2018). So far, and as a result of multiple introductions and range expansion, raccoons are reported in 27 European countries, in 10 of which they are considered invasive and in another 10 established (Fischer et al. 2017; Salgado 2018).

In its native range, raccoons can impact bird populations, especially waterfowl or shorebirds (Zeveloff 2002; Schmidt 2003), turtles (Ratnaswamy and Warren 1998; Karson et al. 2019) and can kill domesticated animals (Zeveloff 2002) or cause damages to fields and crops (Hohmann et al. 2002; Beasley and Rhodes 2008). In Japan, where it was introduced, it was suggested that raccoons have a negative impact on native endangered species (Hayama et al. 2006) and compete with the native raccoon dog (Nyctereutes procyonoides) (Ikeda et al. 2004). However, in Europe there are few studies that investigated the effect of the raccoon on native species and they found no evidence of a negative impact on native prey (Lutz 1984; Horwmann and Schmincke 2004) or competitors (Hohmann and Huppe 1999; Fiderer et al. 2019). On the contrary, raccoons pose a threat to human and animal health because they are carriers, in both their native and introduced range, of several disease agents. Some of these pathogens, such as for example Lyssavirus rabies or Baylisascaris procyonis, can be transmitted to and severely affect humans, domestic animals and other wildlife (Beltrán-Beck et al. 2012; Rentería-Solís et al. 2018; Kornacka et al. 2018).

In 2003 in Lombardy (Italy) the Provincial Police and the Italian Forest Service sighted for the first time the Northern raccoon in areas along the river Adda (Canova and Simone 2008). They captured eight individuals in the Milan Province in order to remove the small nucleus probably accidentally escaped. However, from 2006 more sightings were reported on both sides of the river Adda but removals were only opportunistic. It was initially hypothesized that feral raccoons dispersed from Switzerland (Canova and Simone 2008). However, Mori et al. (2015) showed that the Alps represent a potential barrier between the Italian and the Swiss populations and the hypothesis of individuals escaped/released from captivity seems more likely. Following the European legislation, in 2016 the Lombardy region included the management of alien species in the project "Nature Integrated Management to 2020-LIFE14 IPE/IT/000018", a European co-funded project with the more general aim of biodiversity conservation and management in the Natura 2000 network in the region. The eradication of the raccoon started in 2016 in the Regional Park Adda Nord, a protected area stretching along the river Adda characterized by wetlands, marshes, deciduous woodlands, riparian corridors and man-made areas.

Here we report the steps taken in the eradication campaign of a population of the invasive raccoon in Lombardy (Italy). The aim is to provide information on control methods, the effectiveness of the control campaign and its follow-up. We discuss the management strategies, highlighting success factors and those that jeopardized our objectives and need 
improvement. Finally, we give indications for future control campaigns on the species to increase removal success, reducing the effort.

\section{Materials and Methods}

Study area and eradication plan

The Regional Park Adda Nord is extended along the Adda river and characterized by woodlands, pastures, fields and urban and industrial areas (Supplementary Material 1). Woodlands are dominated by oaks (Quercus sp.), hornbeam (Carpinus betulus), common hazel (Corylus avellana), lime (Tilia cordata), black locust (Robinia pseudoacacia), riparian corridors by willows (Salix sp.), alders (Alnus sp.) and poplar (Populus nigra).

We planned four phases in the campaign with the aim to eradicate the raccoons in the Park.

Phase 1 We initially investigated an area of 120 $\mathrm{km}^{2}$ for the presence of raccoons through visual surveys (sightings or signs), interviews with stakeholders and official reports from the park or municipalities. Based on the results of this first investigation, we trapped from September 2016 to May 2017 in 59 sites covering an area of about $30 \mathrm{~km}^{2}$ (Fig. 1). We used wire cage Tomahawk traps model 205 (Tomahawk Live Trap Co., Tomahawk, Wisconsin, U.S.A.) in 52 sites and EGG Traps (The Egg Trap Company, North Dakota U.S.A.) in seven sites. We modified the Tomahawk traps adding a metal clip on the upper edge of the door to lock it when it closes; this prevented raccoons from opening the traps from the inside. Using a steel chain, we tied both trap types to a trunk or a pole. Traps were baited with a mix of dry cat-food or anchovy paste, and honey, marshmallow or cookies. We checked traps every morning after their activation, for a standard capture session of 4 nights. Raccoons were euthanized by $\mathrm{CO}_{2}$ inhalation following the $\mathrm{EC}$ and AVMA guidelines (Close et al. 1996, 1997; Leary et al. 2013). Permits were issued by the Lombardy Region (permit $n^{\circ}$ 198, 13/01/2017) and ISPRA (Istituto Superiore per la Ricerca Ambientale-Higher Institute of Environmental Research; permit $n^{\circ} 66230$, 15/11/2016).

Phase 2 To better address the trapping effort after the first 8 months of captures, we performed a camera trap survey from April 2017 to September 2017. On an area of $120 \mathrm{~km}^{2}$ along the river we created a grid of $1 \times 1 \mathrm{~km}^{2}$ cells. We randomly placed 3 cameras over 4 cells, so that 3 cells would have 1 camera each and the 4th cell would have no camera (Fig. 2; Rovero and Zimmermann 2016). We surveyed 3 areas for a total of 88 sites (area $\mathrm{A}=30$, area $\mathrm{B}=48$, area $\mathrm{C}=10$ ) using 12 camera traps (6 digital cameras Ltl Acorn 5310WA and 6 Dörr SnapShot mobil 5.1). Each camera was accommodated in an iron box, locked with a padlock and tied to a tree with a chain at $40 \pm 10 \mathrm{~cm}$ from the ground. Cameras were motion/heat activated and were set to take 2 pictures per trigger with a delay time of $3 \mathrm{~s}$ between successive bursts of photos. No lure or bait was used. At each site cameras remained active for 16 consecutive days.

Phase $3 \mathrm{We}$ started a second trapping season in 95 sites from June 2017 to January 2019 to remove the remaining individuals (Fig. 1). To accomplish a fast removal of the individuals detected by cameras, we managed to start trapping in those same sites surveyed by cameras right after the camera trap survey was over. However, we made sure that the subsequent sites monitored by cameras were far from the capture sites not to bias the camera trap survey.

Phase 4 From February 2019 to July 2019 we surveyed the area where the raccoons occurred once more with camera traps to assess the possible presence of last raccoons not caught by traps. In the area where the raccoons occurred, identified during the previous project phases, using the same grid of $1 \times 1 \mathrm{~km}^{2}$ cells of phase 2, we randomly placed 3 cameras in each cell for a total of 99 camera sites surveyed over $33 \mathrm{~km}^{2}$. We used baits in front of the camera traps and doubled the number of cameras in this phase compared to phase 2 (48-99 cameras) to cope with the reduced density of the population after the captures. Cameras were active for 15 days and checked weekly. Moreover, stakeholders were interviewed again and visual surveys were carried out around dismissed buildings and small green patches in the surroundings. In the sites where raccoons were detected by cameras or stakeholders, we activated traps opportunistically to remove the last individuals.

All surveys and captures in the field were carried out by one full-time operator. 


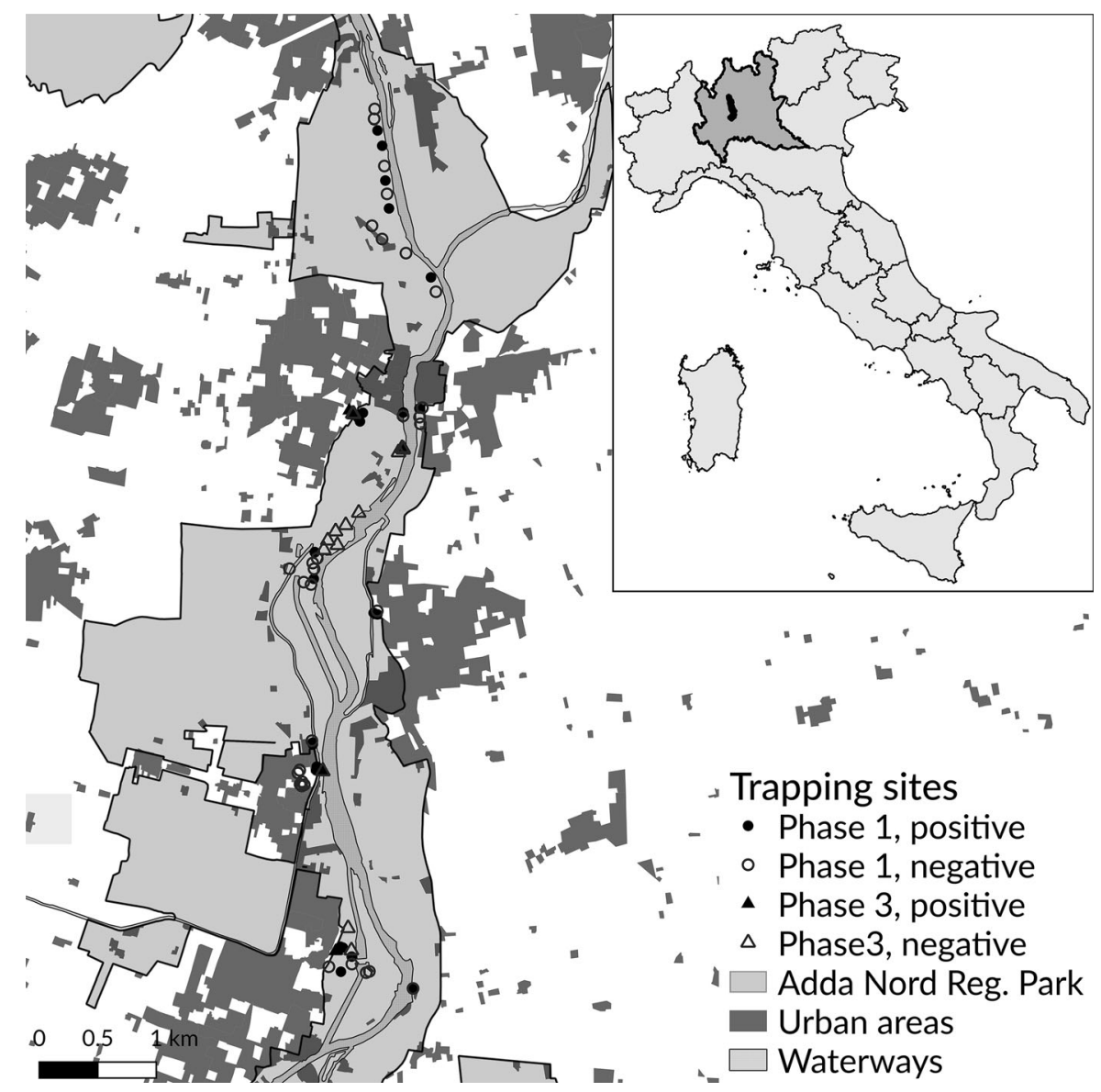

Fig. 1 Trapping sites in the Adda Nord Regional Park (Italy). Circles represent the trapping sites during phase 1 of the project, while triangles the sites active in phase 3 . Symbols are in black if

Data analysis

Using catch-effort data from the trapping program, we estimated the pre-control population size using the deplet maximum likelihood (ML) estimator provided by the R package fishmethods (Nelson 2019), i.e. an implementation of the Gould and Pollock (1997) maximum likelihood estimator, assuming a closed population and a variable effort throughout trapping sessions. The ML estimation was run using 500 bootstrap replicates. For the occupancy analysis using camera trap data, spatial analysis of habitat covariates were performed using the software QGIS v 3.4.5 (QGIS Development Team 2019) and its plugins. For each camera we created a circular buffer of $500 \mathrm{~m}$ radius and merged different layers of the CORINE Land Cover 2018 (https://land.copernicus.eu/pan- raccoons were captured at the site and white if not. Shaded areas indicate: Adda Nord Regional Park (light gray), main waterways of Adda River (medium gray), urban/built areas (dark gray)

european/corine-land-cover/clc2018) into main habitat classes in accordance to raccoon ecology (Supplementary Material 1). The covariates used to model the raccoon detection probability $(p)$ and occupancy $(\psi)$ are reported in Table 1. Pearson's correlation coefficient was used to test for multicollinearity between covariates. Covariate pairs with $r>|0.70|$ were considered highly correlated, hence they were tested in separate occupancy models. Before estimating the model coefficients, covariates were standardized to have mean 0 and unit variance. Data were arranged in a detection matrix where each entry indicated if the raccoon was detected (score $=1$ ) or not (score $=0$ ) at the site during that occasion ( $\mathrm{R}$ package camtrapR, Niedballa et al. 2016). To minimize the risk of non-independent detections at each site, we divided the 16 nights of camera activity into 4 possible 


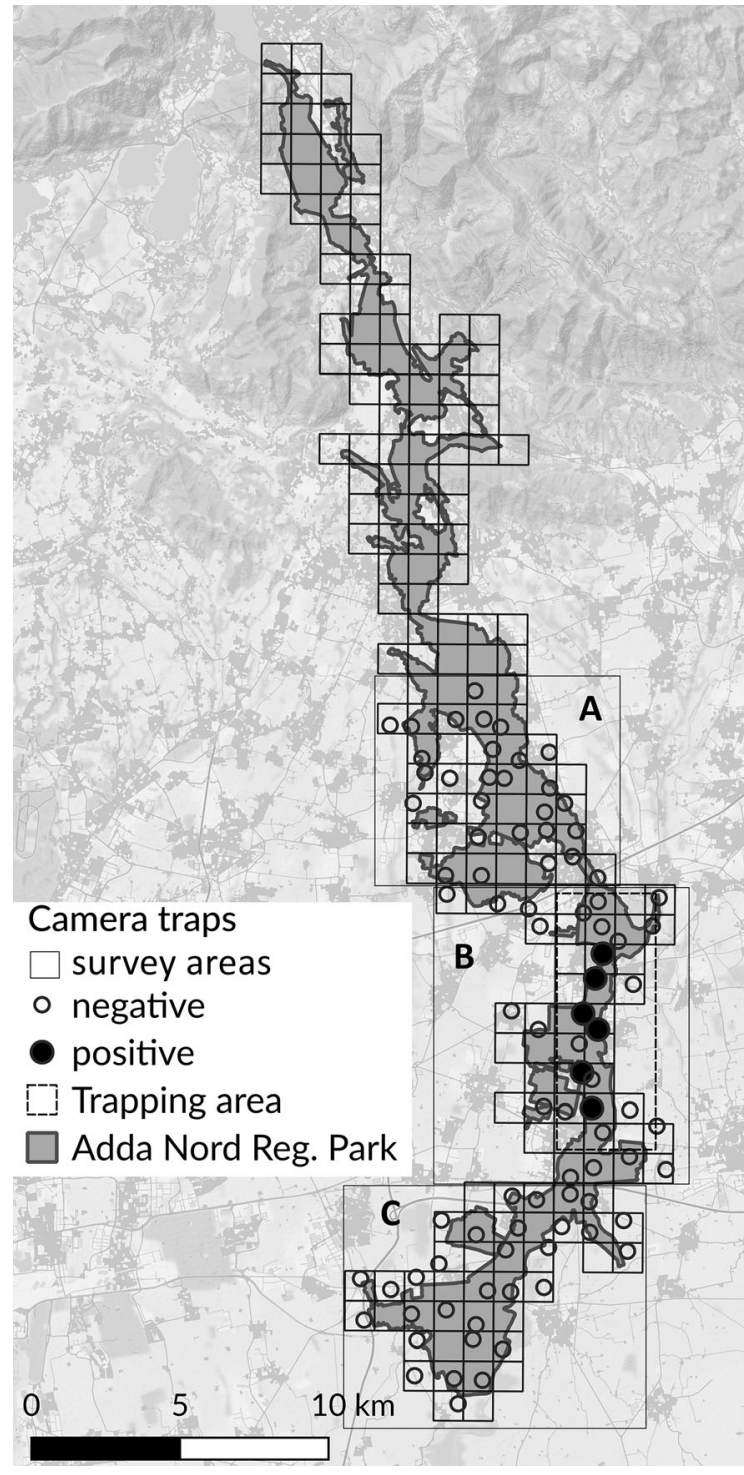

Fig. 2 Camera trap sites in the Adda Nord Regional Park (Italy) during phase 2 of the eradication project. Circles in black are cameras that detected raccoons, white circles that did not. The trapping area of Fig. 1 is indicated by a dashed line

detection events each 4 days long (detection matrix with a 4-day resolution). Doing so, multiple pictures of raccoons within the 4-day period were considered as one detection event. We used the Moran's I test from the $\mathrm{R}$ package ape (weights as the reciprocal of the distances measured; Paradis and Schliep 2019) to check for spatial autocorrelation between detections. We then run a single-species single-season occupancy analysis using the $\mathrm{R}$ package unmarked (Fiske and Chandler 2011). A two-step approach was used to identify the best occupancy models (MacKenzie et al. 2017). We first tested the effects of the covariates on the detection probability $(p)$, whilst keeping the occupancy process $(\psi)$ constant. Covariates were tested both individually and in combination in addition to the null model $(\mathrm{p}()$.$) , for a total of 8$ possible detection models investigated (Table 2). In the second step, the best models for the detection probability $(\triangle \mathrm{AIC}<2)$ were combined with a total of $20 \mathrm{occu}-$ pancy models (Supplementary Material 2) created based on the knowledge of the ecology of the species and the study area. Potentially occupancy processes were limited to a maximum of 2 additive terms. Candidate models were ranked using the AIC value and weight (Burnham and Anderson 2004). Goodness of fit for the best models was checked with the function mb.gof.test (500 replicates) within the $\mathrm{R}$ package AICcmodavg (Mazerolle 2016) to test for overdispersion. Weighted model-averaging was used to produce the final raccoon occupancy and detection probability estimates.

To have a further, independent support to the surveys carried out in phase 4 , we simulated estimation of the probability of eradication using the Rapid Eradication Assessment (REA, REA.is) (SamaniegoHerrera et al. 2013; Russell et al. 2017). As a spatial coverage for the simulation, we used a $1 \mathrm{~km}$ wide buffer surrounding the trapping sites, mostly overlapping the riparian areas along the Adda river. We parametrized REA using the values reported in Supplemental Material 3.

\section{Results}

During the first phase of the project we captured 30 raccoons (M: 12, F: 18) in 17 trapping sites (Fig. 1). All individuals, but one, were captured with wire cage traps.

During phase 2, the 88 camera trap sites were active for a total of 1354 camera trap days. Of the 3 areas surveyed only area B was positive for raccoon presence, hence our analyses were focused on this subset of cameras ( $n=48,720$ camera trap days from June to September 2017). Cameras recorded 13 independent detections of raccoon at 6 sites (naïve occupancy $=0.13$ ) and detections did not show sign of spatial autocorrelation (Moran's I observed $=-0.31$, expected $=-0.20, \quad \mathrm{SD}=0.15, \quad \mathrm{p}=0.48) . \quad$ The 
Table 1 Covariates used to model the detection $(p)$ and occupancy $(\psi)$ of the raccoon in Lombardy (Italy)

\begin{tabular}{lll}
\hline Model component & Covariate & Description \\
\hline Detection $(p)$ & Month & Camera trap working month \\
& Water_dist & $\begin{array}{l}\text { Straight-line distance from camera trap site to the nearest neighbouring water source (m) } \\
\text { Number of individuals removed within each camera buffer }\end{array}$ \\
ind_rem & Area per habitat class $\left(\mathrm{m}^{2}\right)$ \\
Pccupancy $(\psi)$ & Fields & \\
& Urban & \\
Water & \\
& Woods & \\
& Water_dist & Straight-line distance from camera trap site to the nearest neighbouring water source (m) \\
& ind_rem & Number of individuals removed within each camera buffer \\
\hline
\end{tabular}

Table 2 Raccoon detection (p) models

Occupancy $(\psi)$ is kept constant. Models with $\Delta \mathrm{AIC}<2$ in bold

\begin{tabular}{lllllll}
\hline Model & nPars & AIC & delta & AICwt & cumltvWt & Rsq \\
\hline $\boldsymbol{\Psi}$ (.); $\boldsymbol{p}$ (water_dist) & $\mathbf{3}$ & $\mathbf{6 2 . 3 2}$ & $\mathbf{0 . 0 0}$ & $\mathbf{0 . 4 3 5 0}$ & $\mathbf{0 . 4 3}$ & $\mathbf{0 . 2 9 8}$ \\
$\boldsymbol{\Psi}(.) ; \boldsymbol{p}$ (water_dist,ind_rem) & $\mathbf{4}$ & $\mathbf{6 3 . 0 5}$ & $\mathbf{0 . 7 3}$ & $\mathbf{0 . 3 0 2 1}$ & $\mathbf{0 . 7 4}$ & $\mathbf{0 . 3 2 5}$ \\
$\Psi$ (.); $\boldsymbol{p}$ (water_dist,ind_rem,month) & 7 & 64.54 & 2.23 & 0.1430 & 0.88 & 0.413 \\
$\Psi() ;$.$p (water_dist,month)$ & 6 & 65.06 & 2.75 & 0.1102 & 0.99 & 0.365 \\
$\Psi() ;$.$p (month)$ & 5 & 72.17 & 9.85 & 0.0032 & 0.99 & 0.166 \\
$\Psi() ;$.$p (ind_rem)$ & 3 & 72.29 & 9.97 & 0.0030 & 1.00 & 0.063 \\
$\Psi() ;$.$p (.)$ & 2 & 72.66 & 10.34 & 0.0025 & 1.00 & 0.000 \\
$\Psi() ;$.$p (ind_rem,month)$ & 6 & 74.16 & 11.85 & 0.0012 & 1.00 & 0.166 \\
\hline
\end{tabular}

covariates water and fields were correlated $(\mathrm{r}=-0.7)$, hence they were not both included in any of our models. The selection process for the detection probability resulted in 2 top ranking models (Table 2) which were then combined with the 20 a priori occupancy models. Of the 40 models tested, we used the weighted model-averaging on the two top-ranking models (Table 3). These models did not show overdispersion (first model Table 3: $\chi^{2}=11.81$, $\mathrm{p}=0.57, \quad \hat{\mathrm{c}}=0.87 ; \quad$ second model Table 3 : $\left.\chi^{2}=12.74, p=0.52, \hat{c}=0.91\right)$. Raccoon occupancy (estimate $\pm \mathrm{SE}$ ) in area $\mathrm{B}$ was $0.15 \pm 0.09$ and the detection $0.27 \pm 0.07$. The detection process was negatively affected only by the distance from water $(\beta=6.23, \mathrm{SE}=4.0)$, hence detectability increased close to rivers and water basins. Occupancy was affected by two covariates: the urban area (urban), which had a positive effect with occupancy increasing in larger urban areas $(\beta=0.71, \mathrm{SE}=0.91)$; and number of raccoons removed (ind_rem), which also
Table 3 Best raccoon occupancy $(\psi)$ models

Models with $\triangle \mathrm{AIC}<2$ in bold

\begin{tabular}{lllllll}
\hline Model & nPars & AIC & delta & AICwt & cumltvWt & Rsq \\
\hline $\boldsymbol{\Psi}$ (urban, ind_rem); $\boldsymbol{p}$ (water_dist) & $\mathbf{5}$ & $\mathbf{5 2 . 1 1}$ & $\mathbf{0 . 0 0}$ & $\mathbf{5 . 6 e - 0 1}$ & $\mathbf{0 . 5 6}$ & $\mathbf{0 . 5 6}$ \\
$\boldsymbol{\Psi}$ (ind_rem); $\boldsymbol{p}$ (water_dist) & $\mathbf{4}$ & $\mathbf{5 3 . 0 5}$ & $\mathbf{0 . 9 5}$ & $\mathbf{3 . 5 e - 0 1}$ & $\mathbf{0 . 9 1}$ & $\mathbf{0 . 5 1}$ \\
$\Psi$ (water_dist); $\boldsymbol{p}$ (water_dist, ind_rem) & 5 & 59.61 & 7.50 & $1.3 \mathrm{e}-02$ & 0.99 & 0.43 \\
$\Psi$ (urban); $p$ (water_dist) & 4 & 60.66 & 8.55 & $7.8 \mathrm{e}-03$ & 0.99 & 0.37 \\
$\Psi$ (water_dist); $p$ (water_dist) & 4 & 60.94 & 8.83 & $6.8 \mathrm{e}-03$ & 1.00 & 0.37 \\
\hline
\end{tabular}


had a positive relationship indicating a higher occupancy in sites where a higher number of raccoons were previously removed $(\beta=3.39, \mathrm{SE}=1.87$ ) (Supplementary Material 4).

During phase 3, we increased the trapping effort to have a higher chance of trapping the raccoons detected by the camera trap survey. We captured 29 more raccoons (M:12, F: 17) in 22 traps (1 EGG trap, 21 wire cage trap) from June 2017 to September 2018 (Fig. 1). From October 2018 to January 2019 we did not trap any other individual.

Finally, during phase 4 we did not detect any raccoon on 98 cameras (1550 camera trap days) but, thanks to a stakeholder's reports, we captured 10 more raccoons (M:5, F:5) between April and July 2019 activating 16 traps in the reported area.

To summarize the trapping results, we captured a total of 69 raccoons (M:29, F:40; sex ratio MF:0.73). Fifty-nine raccoons were captured during systematic trapping in 34 sites activating a total of 107 trapping sites from September 2016 to January 2019 (6739 cage trap nights; Fig. 3). We captured 10 raccoons between April and July 2019 thanks to an opportunistic activation of 16 traps in 2 sites (540 cage trap nights).
Considering just the systematic trapping effort, the maximum likelihood estimation of population size from catch-effort data based on removal sampling estimated a population size of $65 \pm 7.8$ raccoons (range 49.4-81.5 individuals), with a capture-per-unit effort (number of individuals captured per day) of 0.009 .

Using REA, our results suggest camera trapping for no less than six months without detection would confirm eradication success with greater than $99 \%$ probability, assuming that camera traps cover the entire area occupied by racoons, that no dispersal occurred to neighboring areas and that the probability for a racoon of being detected by a camera trap is near 1.

\section{Discussion}

We carried out a campaign with the aim to eradicate the invasive Northern raccoon along a large river in Northern Italy. We consider the integrated approach used in the campaign successful. In three years, we have removed most of the estimated raccoons in the

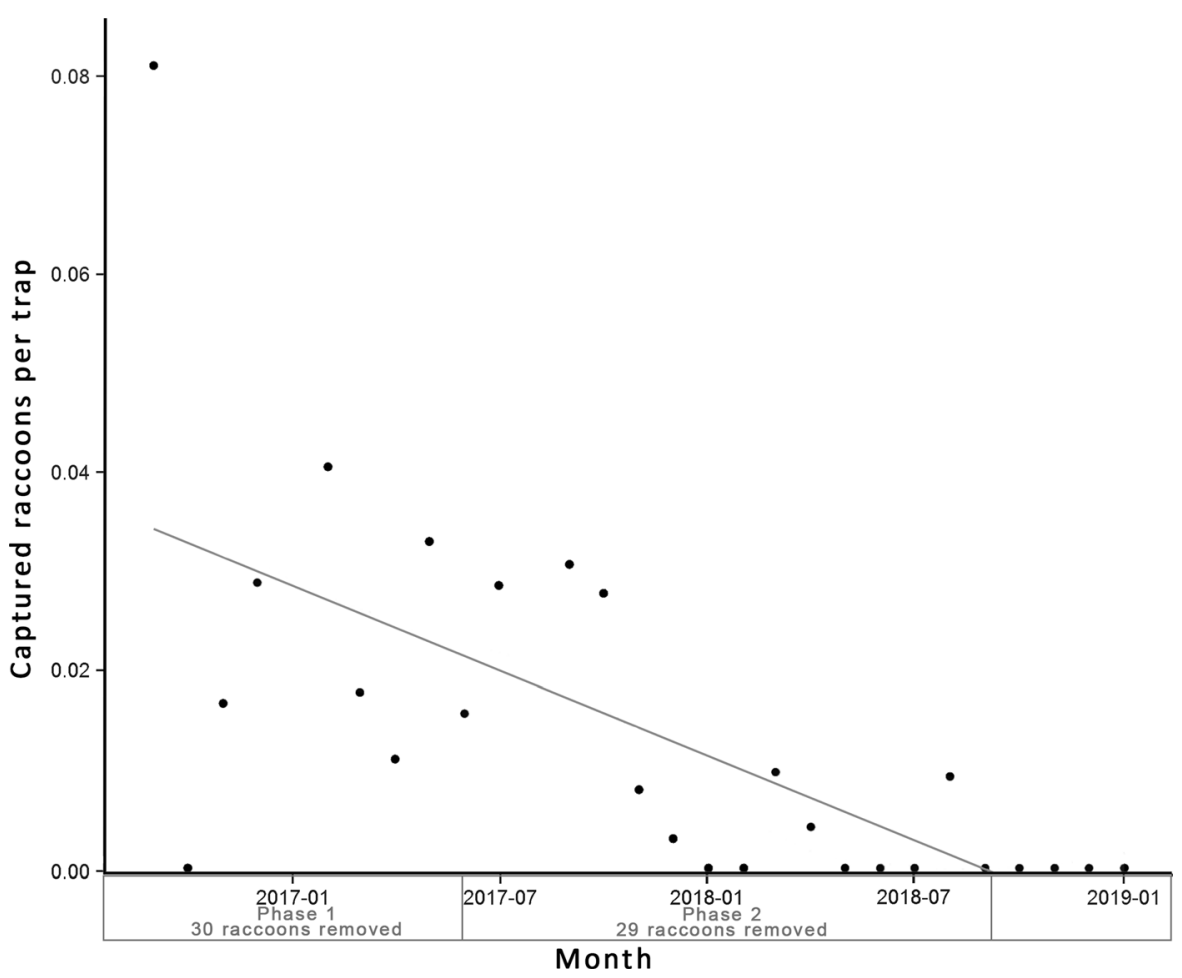

Fig. 3 Individuals removed per trap during the eradication of the raccoon in Lombardy (September 2016-January 2019) 
area and with the help of just one full-time operator. However, since a few more individuals were detected by stakeholders after the systematic survey, we cannot confirm a complete eradication of the population yet, and the area will continue to be surveyed with camera traps to detect possible residual raccoons. The help of stakeholders will be relevant in this final phase.

The integration of camera traps and live traps can be considered the key element for the good results of the campaign. The identification of the intervention area in an eradication program is the first important step. We initially relied on raccoon signs and previous sightings reported by/to the authorities to identify the capture area. However, only $29 \%$ of the trapping sites captured at least one individual. The standardized approach to the camera trap survey in the second phase of the campaign allowed us to identify more in detail the sites where to trap the rest of the population and intensify the trapping effort. Using camera traps in an earlier phase of the control, before the start of the trapping sessions, would have allowed us to better address the trapping effort during the first captures and, probably, maximize the number of captures in a shorter time period.

Thanks to the initial higher density of the population, we removed half of the estimated raccoon population in about 8 months. We used both wire cage traps and EGG traps. Despite EGG traps are reported to perform better at capturing raccoons (Austin et al. 2004), we used more wire caged traps due to the high human density in the area. In fact, EGG traps were only used in closed and fenced sites to prevent any interaction between the trapped animal and people. This is an important factor to be considered when developing a trapping campaign for the raccoon in relation to the type of area where the species occurs (natural vs. urban/suburban).

The camera trap survey in the second phase gave us indication on where to find the remaining nuclei of raccoons and how to increase the trapping success. In fact, the detectability of raccoons increased in the proximity of the Adda river or water basins and the raccoon was not detected more than $1 \mathrm{~km}$ away from the water source. Heske and Ahlers (2016) concluded that the activity of raccoons in Illinois (USA) is positively affected by the availability of water and in Mississipi (USA) it also affects den site selection (Henner et al. 2004). Several studies have reported that water influences the distribution and home range of raccoons both in their native (e.g. Dijak and Thompson 2000; Chamberlain et al. 2007) and introduced range (e.g. Farashi and Naderi 2017; Duscher et al. 2018; Fiderer et al. 2019). However, neither the size of the water source nor the distance from it affected the occupancy of the raccoon in Italy. This lack of evidence could also be related to the low number of sites $(n=6)$ where the raccoons were detected. Raccoons had a higher occupancy in urban areas confirming that human-dominated systems provide this generalist species some benefits. Urbanized areas are a stable, and sometimes abundant, food resource thanks to garbage cans, road litter and animal road kills (Prange et al. 2004; Ladine 2017). Moreover, man-made structures are often used as resting sites (Prange et al. 2003; Michler and Hohmann 2005). This allows the raccoons to reduce their home range, increase their social aggregation and site fidelity and, as a final consequence, increase their density and survival (Michler et al. 2004; Prange et al. 2004; Michler and Hohmann 2005; Bartoszewicz et al. 2008). Despite its high percentage cover in the area, agricultural fields did not affect the occupancy of the raccoon. In their native range, crops represent a food resource for raccoons and their activity increases along forest- cornfield edges (Pedlar et al. 1997; Beasley and Rhodes 2008). However, Heske and Ahlers (2016) concluded that the raccoon activity is better predicted by water availability than any other type of land cover such as agricultural fields, forest or forest-field edge and this is in line with our results, confirming once more the high plasticity of the species. We expected a negative relationship between the occupancy and the number of individuals already removed during the first captures, indicating that those sites where numerous raccoons were removed had a lower occupancy then the others. This hypothesis was not confirmed, and the occupancy was actually higher in those sites. This suggests a clumped distribution of raccoon in our study area (e.g. Wehtje and Gompper 2011; Schuttler et al. 2015) and indicates that the nuclei of the species in those sites had not been completely removed during the first trapping season. Consequently, those sites were subject to an increase in capture effort in the next phase of the campaign.

We need to underline that the camera trap survey was carried out after the removal of half of the raccoon population and this led to a low number of raccoon positive sites. This may have influenced our 
occupancy modeling. As previously stated, we suggest an initial survey with camera traps before any captures to allow in the first place both the definition of the capture area and required trapping effort. Moreover, an initial camera trap survey would also produce more reliable results in the occupancy modeling, that could help in the species management and which results could be compared to other studies in the species native and introduced range.

While during the first part of the campaign we removed half of the population in 8 months, we spent 15 months in the third phase to completely remove the nuclei of raccoons previously identified. The lower density of the population decreased the capture success and we had to increase the number of trapping sites reducing their distance. In fact, when introduced outside their native range, raccoons can have differences in the home range size in relation to the habitat type but also large individual variation in space use (Michler and Hohmann 2005; Bartoszewicz et al. 2008; Fiderer et al. 2019). The closer proximity of traps during phase 3 and camera traps during phase 4 helped in capturing and detecting also the individuals with possible small home ranges. Overall, the capture per unit effort was low but comparable to that reported in a similar habitat in Spain (García et al. 2012). The estimated population size based on catch-effort data revealed that there may be 12 raccoons left to be removed in the worst-case scenario, while the REA simulation confirmed we may be close to the complete eradication of the species. These estimates are important to give the managers an indication on how close the campaign is in reaching its final goal. We are fully aware that both estimates are based on some model assumptions. For example, the catch-effort data analysis is based on the assumption that trappability did not vary among individuals, resulting in a possible population size underestimate due to "trap-shy" individuals (Boitani and Powell 2012). Quantifying the "trappable fraction" of a population could require individual marking, and it lies out of the eradication scenario discussed here. Similarly, REA assumes that all raccoons rely on the riparian vegetation (i.e. can't exist exclusively outside of it) and are eventually detectable by cameras placed in their home range (i.e. do not otherwise avoid camera placements somehow). As for the trappability assumption described above for catch-effort modeling, also eradication assessment modeling depends on assumptions that are reasonable, but difficult to verify. Therefore we believe that the role of "intelligent detectors" played by stakeholders that reported sightings during phase 4 has been essential to identify precisely the sites where potentially "trap-shy" individuals were and activate traps opportunistically to remove them.

During an eradication campaign the support of stakeholders and the public can be decisive for the success of the campaign itself (e.g. Bertolino and Genovesi 2003). García-Llorente et al. (2011) concluded that invasive alien species management needs to engage stakeholders and that their support is influenced by knowledge and perception of invasive alien species' impacts on people, economics, habitats and native wildlife. Before and during raccoon control we informed the stakeholders, mostly farmers and residents, about the threats associated to the presence of the raccoon on the Italian territory and the legislative, ecological and health reasons for its eradication. Most of the stakeholders supported the campaign and some of them played an important role in reporting sightings, signs, and allowing access to their private land. This was an important success for the campaign considering that the raccoon can generate emotional affiliation in the public. Moreover, as previously mentioned, it was thanks to the stakeholders' reports and sightings during phase 4 that we could remove 10 more sparse raccoons that cameras did not detect. This is a clear indication on how our integrated approach is essential for achieving final results.

In conclusion, the approach to the eradication campaign of the raccoon in Italy was successful but the population cannot be considered completely eradicated so far. The next camera trap surveys, with the help of stakeholders' sightings, will be crucial to complete the eradication campaign. A few things can be further improved in future management plans for this species. We suggest the initial use of camera traps to: i) outline the distribution of the population and identify the capture area; ii) carry out occupancy modeling to determine what habitat features influence the detectability and occupancy of the species and gain information on where to set traps to increase the trapping success. The second step is the choice of the type of trap to use in relation to the accessibility of the trapping sites to people (cage wire traps vs EGG/ foot hold trap). During the captures, systematic collection of catch and effort data allows to estimate population size and thus to have a continuous update on how far 
the campaign is from the complete eradication of the species, allowing to adjust the trapping effort accordingly. Camera traps could also be used during the captures to detect other raccoons travelling with the captured one. If the population is wide spread and/or the field operators are not enough in number to cover all of the trapping sites at the same time, camera traps can be used at the trapping sites that are not temporarily active to detect the presence of remaining individuals not captured yet. Hence, we strongly suggest the integrated use of camera traps and traps during the whole campaign. Finally, the social context in which the campaign will take place needs to be considered. Stakeholders can make a big difference in the success of the eradication providing access to their lands, sightings and support during the trapping.

Acknowledgements Open access funding provided by Università degli Studi dell'Insubria within the CRUI-CARE Agreement. Authors thank Alessia Costa and Giulia Pogliani for their valuable technical support in field. We also thank Nicola Ferrari and Claudia Romeo for their veterinarian supervision and the environmental technician of the Adda Nord Regional Park Giuliana Defilippis for her help and collaboration. Thanks to Elisabetta Rossi from the Lombardy Region administration for her valuable and constructive suggestions during the planning and development of this research. Thanks also to the missed colleague Elena Tironi who showed a great interest to this project. We greatly appreciated the time two anonymous reviewers and James Russell spent to provide insightful comments that improved this manuscript during the revision process. This research was funded under the LIFE Gestire 2020 Project (LIFE14 IPE IT 018GESTIRE2020).

Open Access This article is licensed under a Creative Commons Attribution 4.0 International License, which permits use, sharing, adaptation, distribution and reproduction in any medium or format, as long as you give appropriate credit to the original author(s) and the source, provide a link to the Creative Commons licence, and indicate if changes were made. The images or other third party material in this article are included in the article's Creative Commons licence, unless indicated otherwise in a credit line to the material. If material is not included in the article's Creative Commons licence and your intended use is not permitted by statutory regulation or exceeds the permitted use, you will need to obtain permission directly from the copyright holder. To view a copy of this licence, visit http://creativecommons.org/licenses/by/4.0/.

\section{References}

Austin J, Chamberlain MJ, Leopold BD, Burger LW (2004) An evaluation of EGGTM and wire cage traps for capturing raccoons. Wildl Soc Bull 32:351-356. https://doi.org/10. 2193/0091-7648(2004)32[351:AEOEAW]2.0.CO;2

Bartoszewicz M, Okarma H, Zalewski A, Szczęsna J (2008) Ecology of the raccoon (Procyon lotor) from Western Poland. Ann Zool Fenn 45:291-298. https://doi.org/10. 5735/086.045.0409

Beasley JC, Rhodes OE (2008) Relationship between raccoon abundance and crop damage. Hum-Wildl Confl 2:248-259

Beltrán-Beck B, García FJ, Gortázar C (2012) Raccoons in Europe: disease hazards due to the establishment of an invasive species. Eur J Wildl Res 58:5-15. https://doi.org/ 10.1007/s10344-011-0600-4

Bertolino S, Genovesi P (2003) Spread and attempted eradication of the grey squirrel (Sciurus carolinensis) in Italy, and consequences for the red squirrel (Sciurus vulgaris) in Eurasia. Biol Conserv 109:351-358. https://doi.org/10. 1016/S0006-3207(02)00161-1

Boitani L, Powell RA (2012) carnivore ecology and conservation: a handbook of techniques. Oxford University Press, New York

Burnham KP, Anderson DR (2004) Multimodel inference understanding AIC and BIC in model selection. Sociol Methods Res 33:261-304. https://doi.org/10.1177/ 0049124104268644

Canova L, Simone R (2008) First records of the northern raccoon Procyon lotor in Italy. Hystrix Ital J Mammal 19:179-182

Carboneras C, Genovesi P, Vilà M et al (2018) A prioritised list of invasive alien species to assist the effective implementation of EU legislation. J Appl Ecol 55:539-547. https:// doi.org/10.1111/1365-2664.12997

Chamberlain MJ, Austin J, Leopold BD, Burger LW (2007) Effects of landscape composition and structure on core use areas of raccoons (Procyon lotor) in a prairie landscape. Am Midl Nat 158:113-122

Clavero M, García-Berthou E (2005) Invasive species are a leading cause of animal extinctions. Trends Ecol Evol 20:110-110. https://doi.org/10.1016/j.tree.2005.01.003

Close B, Banister K, Baumans V et al (1996) Recommendations for euthanasia of experimental animals: Part 1. Lab Anim 30:293-316

Close B, Banister K, Baumans V et al (1997) Recommendations for euthanasia of experimental animals: Part 2. Lab Anim 31:1-32

Dijak WD, Thompson FR (2000) Landscape and edge effects on the distribution of mammalian predators in missouri. J Wildl Manag 64:209-216

Duscher T, Zeveloff SI, Michler F-U, Nopp-Mayr U (2018) Environmental drivers of raccoon (Procyon lotor L.) occurrences in Austria - established versus newly invaded regions. Arch Biol Sci 70:041-053

European Environment Agency (2013) The impacts of invasive alien species in Europe. Publications Office of the European Union, Luxembourg

Farashi A, Naderi M (2017) Predicting invasion risk of raccoon Procyon lotor in Iran using environmental niche models. Landsc Ecol Eng 13:229-236. https://doi.org/10.1007/ s11355-016-0320-8

Fiderer C, Göttert T, Zeller U (2019) Spatial interrelations between raccoons (Procyon lotor), red foxes (Vulpes vulpes), and ground-nesting birds in a special protection 
area of Germany. Eur J Wildl Res 65:14. https://doi.org/10. 1007/s10344-018-1249-z

Fischer ML, Salgado I, Beninde J et al (2017) Multiple founder effects are followed by range expansion and admixture during the invasion process of the raccoon (Procyon lotor) in Europe. Divers Distrib 23:409-420. https://doi.org/10. 1111/ddi. 12538

Fiske I, Chandler R (2011) Unmarked : an r package for fitting hierarchical models of wildlife occurrence and abundance. J Stat Softw. https://doi.org/10.18637/jss.v043.i10

García JT, García FJ, Alda F et al (2012) Recent invasion and status of the raccoon (Procyon lotor) in Spain. Biol Invasions 14:1305-1310. https://doi.org/10.1007/s10530-0110157-x

García-Llorente M, Martín-López B, Nunes PALD et al (2011) Analyzing the social factors that influence willingness to pay for invasive alien species management under two different strategies: eradication and prevention. Environ Manage 48:418-435. https://doi.org/10.1007/s00267-0119646-z

Gould WR, Pollock KH (1997) Catch-effort maximum likelihood estimation of important population parameters. Can J Fish Aquat Sci 54:890-897. https://doi.org/10.1139/f96327

Hayama H, Kaneda M, Tabata M (eds) (2006) Rapid range expansion of the feral raccoon (Procyon lotor) in Kanagawa Prefecture, Japan, and its impact on native organisms. In: Assessment and control of biological invasion risks. Koike, M N Clout, M Kawamich, M De Poorter, and K Iwatsuki, Shoukadoh Book Sellers Kyoto, Japan and IUCN, GLAND Switzerland, Gland, Switzerland, pp 196-199

Henner CM, Chamberlain MJ, Leopold BD, Burger LW (2004) A multi-resolution assessment of raccoon den selection. J Wildl Manag 68:179-187. https://doi.org/10.2193/0022541X(2004)068[0179:AMAORD]2.0.CO;2

Heske EJ, Ahlers AA (2016) Raccoon (Procyon lotor) activity is better predicted by water availability than land cover in a moderately fragmented landscape. Northeast Nat 23:352-363. https://doi.org/10.1656/045.023.0302

Hohmann U, Bartussek I (2002) Der Waschbär. Tierärztl Prax Ausg Kleintiere Heimtiere 30:32-32

Hohmann U, Huppe K (1999) Interspecific competition of the raccoon (Procyon lotor) and the wildcat (Felis silvestris silvestris) with regard to rest sites in Germany. IUGBProceedings. Thessaloniki, Greece, pp 361-367

Hohmann U, Voigt S, Andreas U (2002) Racoons take the offensive. Curr Assess Neobiota 1:191-192

Horwmann D, Schmincke B (2004) Beobachtungen zur Koexistenz von Mittelspecht und Waschbär. Nat Heim 64:55-60

Ikeda T, Asano M, Matoba Y, Abe G (2004) Present Status of Invasive Alien Raccoon and its Impact in Japan. Glob Environ Res 8(2):125-131

Karson A, Angoh SYJ, Davy CM (2019) Depredation of gravid freshwater turtles by Raccoons (Procyon lotor ). Can FieldNat 132:122-125. https://doi.org/10.22621/cfn.v132i2. 2043

Kettunen M, Genovesi P, Gollasch S, et al (2009) Technical support to EU strategy on invasive alien species (IAS). Inst Eur Environnemental Policy IEEP
Kornacka A, Cybulska A, Popiołek M et al (2018) Survey of Toxoplasma gondii and Neospora caninum in raccoons (Procyon lotor) from the Czech Republic, Germany and Poland. Vet Parasitol 262:47-50. https://doi.org/10.1016/j. vetpar.2018.09.006

Ladine TA (2017) Activity patterns and social organization of raccoons (Procyon lotor) in East Texas. J Wildl Biodivers. https://doi.org/10.22120/jwb.2017.27203

Leary S, Underwood W, Anthony R, et al (2013) AVMA Guidelines for the Euthanasia of Animals: 2013 Edition

Lutz W (1984) The introduced raccoon Procyon lotor population in Germany. Wildl Biol 2:228

Mack RN, Simberloff D, Mark Lonsdale W et al (2000) Biotic invasions: causes, epidemiology, global consequences, and control. Ecol Appl 10:689-710. https://doi.org/10.1890/ 1051-0761(2000)010[0689:BICEGC]2.0.CO;2

MacKenzie DI, Nichols JD, Royle JA et al (2017) Occupancy estimation and modeling: inferring patterns and dynamics of species occurrence. Elsevier, Amsterdam

Mazerolle MJ (2016) AICcmodavg: model selection and multimodel inference based on (Q)AIC(c). Version 2.1-0URL https://CRAN.R-project.org/ packageJAICcmodavg

Michler F-U, Hohmann U (2005) Investigations on the ethological adaptations of the raccoon (Procyon lotor L., 1758) in the urban habitat using the example of the city of Kassel, North Hesse (Germany) and the resulting conclusions for conflict management. Hannover, Germany

Michler F-UF, Hohmann U, Stubbe M (2004) Investigations on daytime resting site selection and home-range of raccoons (Procyon lotor L., 1758) in an urban habitat in Kassel (North Hessen). Bonn, Germany, p 2

Mori E, Mazza G, Menchetti M et al (2015) The masked invader strikes again: the conquest of Italy by the northern raccoon. Hystrix Ital J Mammal 26:47-51. https://doi.org/10.4404/ hystrix-26.1-11035

Nelson GA (2019) Fishmethods: fishery science methods and models. Version 1.11-1URL https://cran.r-project.org/ web/packages/fishmethods/fishmethods.pdf

Niedballa J, Sollmann R, Courtiol A, Wilting A (2016) CamtrapR : an R package for efficient camera trap data management. Methods Ecol Evol 7:1457-1462. https://doi.org/ 10.1111/2041-210X.12600

Paradis E, Schliep K (2019) Ape 5.0: an environment for modern phylogenetics and evolutionary analyses in R. Bioinforma Oxf Engl 35:526-528. https://doi.org/10.1093/ bioinformatics/bty633

Pedlar JH, Fahrig L, Merriam HG (1997) Raccoon habitat Use at 2 spatial scales. J Wildl Manag 61:102-112. https://doi. org/10.2307/3802419

Pimentel D (2011) Biological invasions: economic and environmental costs of alien plant, animal, and microbe species, second edition. CRC Press, Boca Raton

Prange S, Gehrt SD, Wiggers EP (2004) Influences of anthropogenic resources on raccoon (Procyon lotor) movements and spatial distribution. J Mammal 85:483-490. https://doi. org/10.1644/1383946

Prange S, Gehrt SD, Wiggers EP (2003) Demographic factors contributing to high raccoon densities in urban landscapes. J Wildl Manag 67:324-333. https://doi.org/10.2307/ 3802774 
QGIS Development Team (2019) Quantum GIS. Version 3.4.5. Open Source Geospatial Foundation Project. URL https:// qgis.osgeo.org

Ratnaswamy MJ, Warren RJ (1998) Removing Raccoons to Protect Sea Turtle Nests: Are There Implications for Ecosystem Management? Wildl Soc Bull 1973-2006(26):846-850

Rentería-Solís Z, Birka S, Schmäschke R et al (2018) First detection of Baylisascaris procyonis in wild raccoons (Procyon lotor) from Leipzig, Saxony, Eastern Germany. Parasitol Res 117:3289-3292. https://doi.org/10.1007/ s00436-018-5988-2

Rovero F, Zimmermann F (2016) Camera Trapping for Wildlife Research. Pelagic Publishing Ltd, Exeter, UK

Russell JC, Binnie HR, Oh J et al (2017) Optimizing confirmation of invasive species eradication with rapid eradication assessment. J Appl Ecol 54:160-169. https://doi.org/ $10.1111 / 1365-2664.12753$

Salgado I (2018) Is the raccoon (Procyon lotor) out of control in Europe? Biodivers Conserv 27:2243-2256. https://doi.org/ 10.1007/s10531-018-1535-9

Samaniego-Herrera A, Anderson DP, Parkes JP, AguirreMuñoz A (2013) Rapid assessment of rat eradication after aerial baiting. J Appl Ecol 50:1415-1421. https://doi.org/ 10.1111/1365-2664.12147

Scalera R (2010) How much is Europe spending on invasive alien species? Biol Invasions 12:173-177. https://doi.org/ 10.1007/s10530-009-9440-5
Schmidt KA (2003) Nest predation and population declines in illinois songbirds: a case for mesopredator effects. Conserv Biol 17:1141-1150. https://doi.org/10.1046/j.1523-1739. 2003.02316.x

Schuttler SG, Ruiz-López MJ, Monello R et al (2015) The interplay between clumped resources, social aggregation, and genetic relatedness in the raccoon. Mammal Res 60:365-373. https://doi.org/10.1007/s13364-015-0231-3

Strayer DL (2012) Eight questions about invasions and ecosystem functioning. Ecol Lett 15:1199-1210. https:// doi.org/10.1111/j.1461-0248.2012.01817.x

Tollington S, Turbé A, Rabitsch W et al (2017) Making the EU legislation on invasive species a conservation success: invasive alien species policy in Europe. Conserv Lett 10:112-120. https://doi.org/10.1111/conl.12214

Wehtje M, Gompper ME (2011) Effects of an experimentally clumped food resource on raccoon Procyon lotor homerange use. Wildl Biol 17:25-32. https://doi.org/10.2981/ 10-012

Zeveloff SI (2002) Raccoons: a natural history. UBC Press, Vancouver/Toronto

Publisher's Note Springer Nature remains neutral with regard to jurisdictional claims in published maps and institutional affiliations. 